\title{
Urinálise: comparação entre microscopia óptica e citometria de fluxo
}

\author{
Urinalysis: comparison between microscopic and flow cytometry analysis
}

Bottini P.V. ${ }^{1}$; Garlipp C.R. ${ }^{2}$

\begin{abstract}
unitermos resumo
Urinálise

Introdução e objetivo: O exame de urina é um procedimento de alta demanda, trabalhoso e pouco padronizado. Este estudo teve por objetivo avaliar o desempenho de um citômetro de fluxo na realização

Microscopia óptica comum do exame de urina de rotina. Casuística e métodos: Foram analisadas 1.140 amostras de urina através Citometria de fluxo de microscopia óptica comum e de citometria de fluxo (UF-100/SYSMEX). A precisão foi estabelecida com a análise de quatro amostras de urina (20 replicações cada). O cálculo da reprodutibilidade foi realizado a partir de 30 determinações de dois controles comerciais em dias consecutivos. Resultados: As contagens de hemácias e leucócitos mostraram concordância de $91 \%$ e 93\%, respectivamente. Cilindros, células e bactérias mostraram sobreposição dos valores fornecidos pelo UF-100 quando comparados com os relatados na análise microscópica. A precisão do UF-100 variou de $4 \%$ a $155 \%$, com reprodutibilidade de $3 \%$ e $25 \%$, dependendo do parâmetro avaliado. Conclusão: O equipamento UF-100/SYSMEX demonstra boa precisão, reprodutibilidade e concordância com a microscopia óptica. A utilização da citometria de fluxo implica numa maior agilização e padronização da rotina, bem como em uma nova maneira de reportar e interpretar o exame de urina de rotina.
\end{abstract}

Introduction: Urinalysis is a high demand procedure, with large amount of manual labor and poorly standardized. The purpose of this investigation was to analyze the performance of an automated system based on flow cytometry for routine urinalysis. Material and methods: We analyzed 1,140 urine samples by light field microscopy and by flow cytometry (UF-100/SYSMEX). For the precision study of the UF-100, we calculated the within-run and between-run coefficients of variation using two different levels of commercial controls and four different urine samples. Results: Erythrocytes and leukocytes counts by the two methods showed an agreement of $91 \%$ and $93 \%$, respectively. Casts, epithelial cells and bacteria counts by the UF-100 showed a significant overlap when compared to microscopic analysis. Intra assay precision (within-run) ranged from $4 \%$ to $155 \%$ and interassay precision (between-run) varied from $3 \%$ to $25 \%$, depending on the considered parameter. Conclusion: Flow cytometry is a precise and reproducible technique, with a strong correlation with the results obtained by microscopic analysis. Flow cytometry allows a better workflow and a new manner of reporting and interpreting routine urinalysis.

1. Médica patologista clínica; supervisora do Serviço de Líquidos Biológicos da Divisão de Patologia Clínica do Hospital de Clínicas da Universidade Estadual de Campinas (HC/UNICAMP). 2. Professora associada do Departamento de Patologia Clínica da Faculdade de Ciências Médicas (FCM) da UNICAMP.

Divisão de Patologia Clínica do HC/UNICAMP. 


\section{Introdução}

Embora a análise do sedimento urinário forneça informações essenciais sobre o estado funcional dos rins, o exame de urina é um procedimento de alta demanda que requer um trabalho intenso, é pouco padronizado e apresenta uma ampla variabilidade interobservadores ${ }^{(13)}$. Adicionalmente, esse exame gera um custo elevado aos laboratórios, já que para se obter resultados de qualidade há a necessidade de pessoal bastante qualificado ${ }^{(2)}$. Atualmente, tanto o National Committee for Clinical Laboratory Standards (NCCLS) dos EUA $^{(11)}$ como o European Urinalysis Guidelines ${ }^{(5)}$ recomen- $^{-}$ dam a padronização da contagem de células do exame de urina, por meio de um sistema automatizado e/ou de um procedimento padronizado em uma câmara de contagem de células de volume pré-definido ${ }^{(12)}$.

$\mathrm{Na}$ tentativa de se automatizar a análise microscópica da urina, no final dos anos 1980, surgiram alguns sistemas analisadores de imagens. Esses equipamentos, apesar de melhorarem o fluxo de trabalho e aumentarem a produtividade e precisão das análises, ainda são bastante dependentes de um observador bem treinado(4)

Há alguns anos surgiu no mercado um equipamento que realiza a análise da urina por citometria de fluxo, o UF-100/SYSMEX. Esse equipamento é um analisador totalmente automatizado, que aspira a amostra de urina e, por fluorescência, cora o DNA e as membranas dos elementos formados na urina nativa (fenantridina para ácidos nucleicos e carbocianina para membranas celulares). A seguir, células, bactérias e cilindros são analisados e classificados, levando-se em consideração o volume (impedância), o tamanho (dispersão de luz) e as características tintoriais (fluorescência) nucleares e citoplasmáticas dos elementos urinários ${ }^{(6)}$. A distinção entre hemácias e leveduras é feita de acordo com a intensidade de suas fluorescências.

Apesar de a análise microscópica da urina demandar enorme trabalho laboratorial manual e de apresentar precisão limitada, ainda é universalmente utilizada para o exame de células e partículas presentes na urina. Quando comparados com a microscopia óptica comum, os citômetros de fluxo melhoraram a precisão e a eficácia das contagens, gerando uma substancial redução do trabalho. No entanto, a falta de padronização nos seus procedimentos analíticos permanece um importante fator limitante para sua ampla utilização.

\section{Objetivo}

Este estudo teve por objetivo avaliar o desempenho de um citômetro de fluxo (UF-100/SYSMEX), frente a análises microscópicas do sedimento urinário, em um hospital de atendimento terciário.

\section{Casuística}

Foram avaliadas 1.140 amostras isoladas de urina (jato médio), encaminhadas ao laboratório a pedido médico, para análise de rotina (exame físico-químico e análise do sedimento urinário) na Seção de Urinálise da Divisão de Patologia Clínica do Hospital de Clínicas da Universidade Estadual de Campinas (HC/UNICAMP).

Este estudo obteve a dispensa da assinatura do termo de consentimento livre e esclarecido, uma vez que os testes laboratoriais foram realizados com o excedente das amostras de urina encaminhadas para o diagnóstico e tratamento dos pacientes atendidos em nosso Serviço. O anonimato dos indivíduos foi preservado, segundo os critérios estabelecidos pela Resolução 196/96 e observados pelo Comitê de Ética da Faculdade de Ciências Médicas (FCM) da UNICAMP.

\section{Métodos}

Todas as amostras foram analisadas por microscopia óptica comum e por citometria de fluxo. Para análise microscópica do sedimento, as amostras foram inicialmente homogeneizadas e submetidas a centrifugação $(10 \mathrm{ml}$ de urina a $1.500 \mathrm{rpm} / \mathrm{min}$, durante 10 minutos). O sobrenadante foi desprezado, restando $1 \mathrm{ml}$ de sedimento, que foi ressuspenso por agitação e transferido para um pocinho da lâmina padronizada (KCELL).

O sedimento foi inicialmente analisado (aumentado em 100 vezes) para verificar a disposição dos elementos presentes na área não-demarcada por círculos. A contagem de hemácias e leucócitos foi realizada com aumento de 400 vezes, sendo contados pelo menos 10 campos e o resultado expresso em número médio de leucócitos e hemácias por campo. A presença de bactérias, cilindros, cristais e células epiteliais foi expressa de maneira semiquantitiativa (Tabelas 1 e 2).

Para análise por citometria de fluxo utilizou-se o equipamento UF-100/SYSMEX. As amostras foram homogeneizadas e transferidas para tubos de $10 \mathrm{ml}$, os quais 
Tabela 1

\section{Expressão dos resultados: hemácias}

$N^{0}$ médio/campo

Descrição

$<1$

Inferior a $1 /$ campo

Entre 1 e 100

Número/campo

$>100$

Superior a 100/campo

\begin{tabular}{cc} 
Tabela 2 & cristais e células epiteliais \\
\hline$N^{0}$ médio/campo & Descrição \\
0 & Ausentes \\
$<1$ & Raros \\
1 a 3 & Número regular \\
$>3$ & Numerosos \\
\hline
\end{tabular}

foram colocados em racks do equipamento. Este realizou a aspiração da amostra e o processamento automatizado da contagem dos elementos figurados presentes na urina. Os resultados foram expressos de forma gráfica e numérica (elementos por $\mu$ l e por campo).
A precisão do UF-100 foi estabelecida a partir da análise de quatro amostras de urina (20 replicações cada), sendo o cálculo da reprodutibilidade realizado a partir de 30 determinações de dois controles comerciais, em dias consecutivos.

\section{Análise estatística}

A análise estatística se baseia em testes de concordância (através da construção de tabelas $2 \times 2$ com posterior análise pelo $\chi^{2}$ ) e em cálculos de sensibilidade, especificidade e valores preditivos positivos e negativos, conforme recomendação do fabricante do equipamento.

\section{Resultados}

O estudo da precisão do UF-100 (Tabelas 3 e 4) apresentou coeficientes de variação (CV) intra-ensaios de $5 \%$ a 21\% (hemácias); $4 \%$ a 24\% (leucócitos); $5 \%$ a 35\% (células epiteliais); $66 \%$ a $155 \%$ (cilindros) e $4 \%$ a $6 \%$ (bactérias).

A reprodutibilidade (coeficiente de variação [CV] interensaio, Tabelas 5 e 6) variou entre $3 \%$ e $25 \%$, dependendo do parâmetro avaliado.

Tabela 3 Precisão do UF-100/CV intra-ensaio: hemácias e leucócitos

\begin{tabular}{lcccccccc}
\hline \multicolumn{9}{c}{ Hemácias* $^{*}$ Leucócitos* } \\
Replicatas & 20 & 20 & 20 & 20 & 20 & 20 & 20 & 20 \\
Média & 39 & 5 & 4 & 0,2 & 106 & 2 & 22 & 0,5 \\
Mínimo & 34 & 4 & 3 & 0,2 & 101 & 1 & 18 & 0,3 \\
Máximo & 42 & 7 & 4 & 0,3 & 115 & 2 & 30 & 0,7 \\
Desvio-padrão & 2 & 1 & 0,4 & 0,1 & 4 & 0,1 & 3 & 0,1 \\
CV (\%) & 5 & 12 & 9 & 21 & 4 & 9 & 13 & 24 \\
\hline
\end{tabular}

*Contagem/campo.

\section{Tabela 4 Precisão do UF-100/CV intra-ensaio: células epiteliais, cilindros e bactérias}

\begin{tabular}{lcccccccccccc}
\hline & \multicolumn{1}{c}{ Células* } & \multicolumn{1}{c}{ Cilindros* } & \multicolumn{1}{c}{ Bactérias* } \\
Replicatas & 20 & 20 & 20 & 20 & 20 & 20 & 20 & 20 & 20 & 20 & 20 & 20 \\
Média & 14 & 1 & 7 & 0,3 & 1,0 & 0,3 & 0,3 & 0,2 & 1087 & 136 & 694 & 81 \\
Mínimo & 13 & 1 & 6 & 0,1 & 0 & 0 & 0 & 0 & 858 & 124 & 564 & 75 \\
Máximo & 16 & 2 & 10 & 0,5 & 3 & 1 & 1 & 1 & 1176 & 147 & 728 & 89 \\
Desvio-padrão & 1 & 0,2 & 1 & 0,1 & 0,7 & 0,3 & 0,4 & 0,3 & 68 & 6 & 35 & 3 \\
CV (\%) & 5 & 15 & 14 & 35 & 66 & 121 & 109 & 155 & 6 & 4 & 5 & 4 \\
\hline
\end{tabular}

*Contagem/campo. 


\section{Tabela 5 Reprodutibilidade/CV interensaio: hemácias e leucócitos}

\begin{tabular}{|c|c|c|c|c|}
\hline \multirow[b]{2}{*}{ Replicatas (CQ 1 E 2) } & \multicolumn{2}{|c|}{ Hemácias* } & \multicolumn{2}{|c|}{ Leucócitos* } \\
\hline & 30 & 30 & 30 & 30 \\
\hline Média & 40 & 201 & 42 & 196 \\
\hline Mínimo & 31 & 187 & 33 & 187 \\
\hline Máximo & 48 & 210 & 51 & 207 \\
\hline Desvio-padrão & 4 & 6 & 5 & 6 \\
\hline CV $(\%)$ & 10 & 3 & 11 & 3 \\
\hline
\end{tabular}

* Contagem $/ \mu l$.

\section{Tabela 6 Reprodutibilidade/CV interensaio: células, cilindros e bactérias}

\begin{tabular}{lcccccc}
\hline & \multicolumn{2}{c}{ Células* $^{*}$} & \multicolumn{2}{c}{ Cilindros* } & \multicolumn{2}{c}{ Bactérias* } \\
Replicatas (CQ 1 e 2) & 30 & 30 & 30 & 30 & 30 & 30 \\
Média & 12 & 95 & 6 & 21 & 2.975 & 981 \\
Mínimo & 8 & 92 & 5 & 15 & 2.026 & 569 \\
Máximo & 18 & 105 & 8 & 25 & 3.763 & 1.328 \\
Desvio-padrão & 2 & 4 & 2 & 3 & 43 & 21 \\
CV (\%) & 19 & 5 & 25 & 13 & 1 & 2 \\
\hline
\end{tabular}

${ }^{*}$ Contagem $/ \mu l$.

As contagens de hemácias e leucócitos mostraram concordância entre os métodos de $91 \%$ e $93 \%$, respectivamente, com valor preditivo (VP) negativo superior a $97 \%$ quando consideramos como limite de normalidade uma contagem de até cinco elementos/campo $(p<0,05)$ (Tabelas $\mathbf{7}$ e $\mathbf{8}$ ).

Em relação a cilindros, células e bactérias (Figuras 1, 2e 3), observamos uma grande sobreposição das contagens forne- cidas pelo UF-100 quando comparados com os relatados na análise microscópica, onde foram expressos como ausentes, raros, regular número e numerosos.

O principal interferente nas contagens de cilindros foi a presença de filamentos de muco, enquanto leveduras e cristais de oxalato de cálcio discóides foram os principais responsáveis por contagens de hemácias falsamente elevadas.

\section{Tabela 7 Concordância entre as contagens de hemácias}

\begin{tabular}{lccc}
\hline & $>5 /$ campo (M0) & até 5/campo (MO) & Total \\
$>5 /$ campo (UF 100) & 141 & 77 & 218 \\
até 5/campo (UF 100) & 31 & 891 & 922 \\
Total & 172 & 968 & 1140 \\
\hline
\end{tabular}

Sensibilidade $=82 \%$; especificidade $=92 \%$; VP positivo $=65 \%$; VP negativo $=97 \%$; concordância $=91 \%$.

\section{Tabela 8 Concordância entre as contagens de leucócitos}

\begin{tabular}{lccc}
\hline & $>5 /$ campo (M0) & até 5/campo (MO) & Total \\
$>5 /$ campo (UF 100) & 25 & 61 & 312 \\
até 5 / campo (UF 100) & 15 & 813 & 828 \\
Total & 266 & 874 & 1.140 \\
\hline
\end{tabular}

Sensibilidade $=94 \%$; especificidade $=93 \% ;$ VP positivo $=80 \% ;$ VP negativo $=98 \%$; concordância $=93 \%$. 


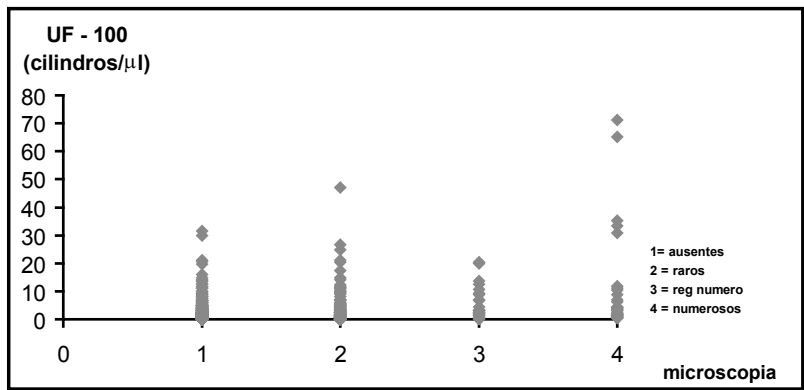

Figura 1 - Relação entre microscopia ótica e citometria de fluxo - cilindros

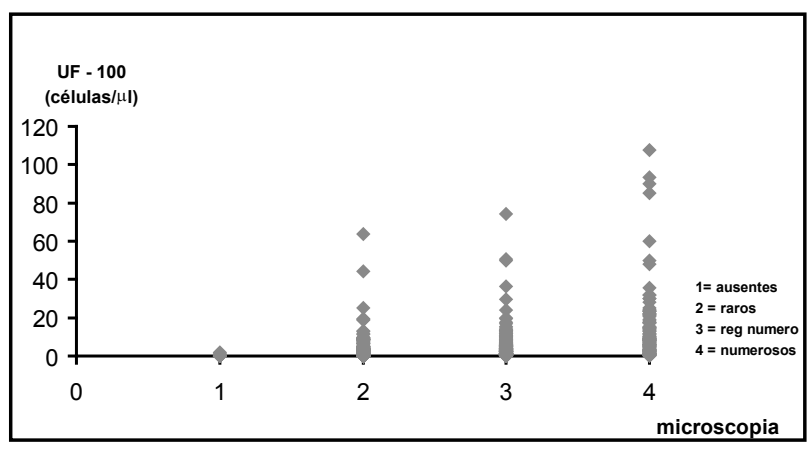

Figura 2 - Relação entre microscopia ótica e citometria de fluxo - células epiteliais

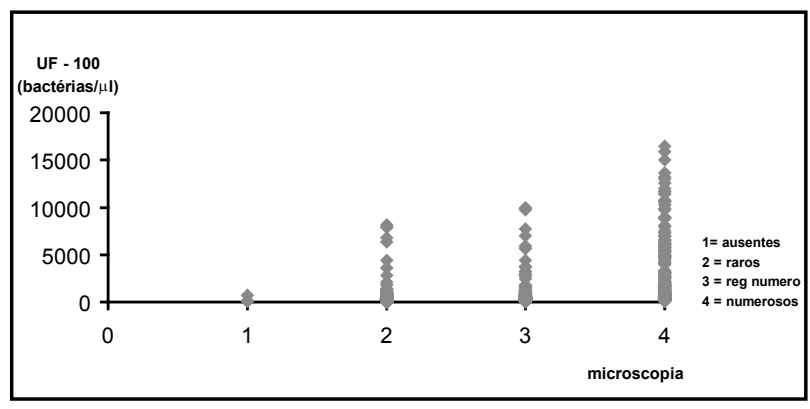

Figura 3 - Relação entre microscopia ótica e citometria de fluxo - bactérias

\section{Discussão}

A análise manual do sedimento urinário, embora de grande utilidade clínica, apresenta muitos problemas metodológicos. Além de consumir considerável tempo de trabalho do analista, vários fatores podem contribuir para a imprecisão nos resultados desse método (centrifugação, diferenças de interpretação de elementos celulares, cilindros, entre outros) ${ }^{(2)}$.

O analisador UF-100 identifica na urina, pelo princípio da citometria de fluxo, células e partículas de maneira análoga à dos analisadores de células sangüíneas. Portanto é um equipamento totalmente automatizado, multiparamétrico e com boa velocidade de processamento (em torno de 100 amostras/hora). Em relação à análise estatística, o fabricante do equipamento recomenda o uso de testes de comparação dos resultados entre metodologias (microscopia $\mathrm{x}$ automa- ção), com base em cálculos de taxas de concordância das amostras consideradas negativas ou normais.

Estudos têm relatado uma boa correlação entre o número de células contadas por microscopia óptica e citometria de fluxo ${ }^{(1)}$. De fato, nossos resultados apresentaram boa concordância entre as duas metodologias quando consideramos o limite de normalidade de até cinco elementos/campo (hemácias ou leucócitos). Além disso, o UF-100 vem se mostrando bastante preciso e com boa reprodutibilidade, o que foi demonstrado neste e em outros estudos ${ }^{(2,7,12)}$. Já com relação aos cilindros, o elevado coeficiente de variação intra-ensaio observado em nosso estudo se deve ao pequeno número de cilindros presentes no material analisado.

Vários autores ${ }^{(2,12)}$ vêm demonstrando que o UF-100 detecta mais hemácias, leucócitos e células epiteliais do que a microscopia manual. Isto provavelmente representa a detecção real de elementos que não são identificados pela microscopia óptica, uma vez que a rotina de urinálise compreende várias etapas, como centrifugação, decantação e ressuspensão, as quais podem levar a uma perda e/ou degeneração celular variável. Além desses fatores, até a matéria-prima do tubo cônico para centrifugação pode ser mais um fator de variação, podendo ocorrer, ou não, adsorção de elementos celulares às suas paredes ${ }^{(8,10)}$. Provavelmente, essa observação justifica uma das maiores dificuldades de sua implantação na rotina da maioria dos laboratórios, que reside no fato de seus valores de referência serem significativamente diferentes e mais elevados do que os habitualmente adotados.

No presente trabalho, o principal interferente nas contagens de cilindros foi a presença de filamentos de muco, enquanto leveduras e cristais de oxalato de cálcio discóides foram os principais responsáveis por contagens de hemácias falsamente elevadas. Outros autores ${ }^{(2)}$ observaram que o UF-100 superestimava a contagem de células epiteliais na presença de cilindros, Trichomonas sp. e proteinúria. Nesse último caso a explicação seria a formação de grumos leucocitários devido à presença de proteínas na amostra.

Vários relatos fazem referência à contagem incorreta de hemácias na presença de cristais, leveduras, espermatozóides e grande número de bactérias $9,10,12)$ Da mesma forma, a principal causa de contagem de leucócitos falsamente elevados é a presença de núcleos isolados de células epiteliais ${ }^{(12)}$.

Segundo Ottiger e Huber ${ }^{(12)}$, a maior parte das revisões pode ser atribuída a alertas decorrentes da presença de células redondas (SRC), cilindros, cristais, leveduras e espermatozóides. Células epiteliais agrupadas freqüentemente dão um alerta para cilindros patológicos e SRC que necessitam de confirmação. Grande número de cristais, leveduras e espermatozóides superestimam a contagem de hemácias, como foi comprovado em nosso estudo. 
$\mathrm{Na}$ análise dos dados relativos a cilindros, células e bactérias, em razão da sobreposição dos valores fornecidos pelo UF-100 quando comparados com os relatados na análise microscópica, é necessário estabelecer uma nova maneira de expressar esses resultados em substituição à forma de expressão semiquantitativa habitualmente utilizada, ressaltando-se a presença ou ausência desses elementos.

A correta identificação de cilindros e cristais patológicos ainda necessita ser realizada através de microscopia óptica tradicional. Da mesma forma, deve-se ressaltar que todas as amostras que apresentem alertas (flags) ou elementos anormais devem ser submetidas à revisão microscópica. Vale lembrar que amostras de urina proveniente de serviços de nefrologia apresentam maior taxa de revisão(3).

Para o estabelecimento de um algoritmo que reduza o trabalho manual, permitindo maior otimização das rotinas sem perda de sensibilidade e especificidade, deve-se levar em conta contagens celulares elevadas, presença de cilindros, cristais, leveduras, espermatozóides, além de alertas para elementos patológicos e da análise detalhada dos gráficos de dispersão para detectar um possível padrão anormal.
Antes da liberação final é prudente associar uma checagem cruzada entre os resultados obtidos na análise físico-química (através de tiras reagentes) com os dados fornecidos pelo UF-100.

\section{Conclusão}

Nossos resultados demonstram que o equipamento UF-100 apresenta boa precisão, reprodutibilidade e concordância com a microscopia óptica. Os dados apresentados confirmam a dificuldade de padronização e a subjetividade da análise microscópica do exame de urina. A utilização rotineira da citometria de fluxo implica em maior agilização e padronização da rotina, ao lado de uma nova maneira de se reportar e interpretar o exame de urina de rotina.

\section{Agradecimentos}

A Bruna de Carvalho Gallo, João Guilherme A. P. Franceschi, José Ricardo Lauand e a Susy Helena Afaz pela ajuda inestimável na compilação dos dados.

\section{Referências}

I. ANDRIOLO, A. et al. Avaliação de um sistema totalmente automatizado para a realização do exame de urina de rotina: urina tipo I. NewsLab, v. 36, p. 76-80, 1999.

2. BEN-EZRA J.; BORK, L.; MACPHERSON, R.A. Evaluation of the Sysmex UF- 100 automated urinalysis analyzer. Clin Chem v. 44, p. 92-95, 1998.

3. DELANGHE J.R. et al. The role of automated urine particle flow cytometry in clinical practice. Clin Chim Acta, v. 30I, p. I- I8, 2000.

4. DIMECH, W.; RONEY, K. Evaluation of an automated urinalysis system for testing urine chemistry, microscopy and culture. Pathology, v. 34, p. 170-7, 2002

5. EUROPEAN CONFEDERATION OF LABORATORY MEDICINE. European urinalysis guidelines. Scand J Clin Lab Invest, v. 60, s. 23I, p. I-86, 2000.

6. FENILI, D.; PIROVANO, B. The automation of sediment urinalysis using a new urine flow cytometer (UF-100). Clin Chem Lab Med, v. 36, n. 12, p. 909-17, 1998.

7. KEIJZER, M.H.; BRANDTS, R.W. Flow cytometry and the urine laboratory: field evaluation of the SYSMEX UF- I00.SYSMEX J Int, v. 7, p. I 17-22, 1997
8. KIMY. et al. Quantitative analysis of urine sediment using newly designed centrifuge tubes. Ann Clin Lab Sci, v. 32, p. 55-60 2002.

9. KOURI T.T. et al. Evaluation of SYSMEX UF-IO0 urine flow cytometer vs. chamber counting of supravitally stained specimens and conventional bacterial cultures. Am J Clin Pathol, v. I I 2, p. 25-35, 1999

10. LANGLOIS M.R. et al. Automated flow cytometry compared with an automated dipstick reader for urinalysis. Clin Chem, v. 45, p. I | 8-22, 1999.

I।. NATIONAL COMMITTEE FOR CLINICAL LABORATORY STANDARDS. Urinalysis and collection, transportation and preservation of urine specimens; approved guideline: NCCLS document GP 16-A. Wayne, PA: NCCLS, 1995.

12. OTTIGER, C.; HUBER, A.R. Quantitative urine particle analysis: integrative approach for the optimal combination of automation with UF-IO0 and microscopic review with KOVA cell chamber. Clin Chem, v. 49, p. 617-23, 2003.

I3.WINKEL, P.; STATLAND, B.E.; JRGENSEN, K. Urine microscopy, an ill defined method, examined by a multifactorial technique. Clin Chem, v. 20, p. 436-9, 1974. 